\title{
STUDIES ON THE EFFECT OF TWO SALEN SCHIFF-BASES ON THE CORROSION OF LOW ALLOY STEEL IN 1M HCL
}

\author{
FATEMEH BAGHAEI RAVARI ${ }^{*}$, ATHAREH DADGARINEZHAD ${ }^{a}$, IRAN SHEKHSHOAEI $^{b}$
}

${ }^{a}$ Department of Materials Science \& Engineering, Faculty of Engineering, Shahid Bahonar University, Kerman, Iran.

${ }^{b}$ Department of Chemistry, Shahid Bahonar University, Kerman, Iran

(Received: September 14, 2009 - Accepted: April 29, 2010)

\begin{abstract}
The corrosion inhibition by two synthesized Schiff -bases of bis-(2-hydroxy-3-methoxy)-1,6-diaminohexane salicyladimine and bis- (2-hydroxy)1,6-diaminohexane salicyladimine was investigated by weight loss, Tafel polarization and AC impedance on low alloy steel in $1 \mathrm{M}$ HCl. The results show that these Schiff -bases act as anodic type inhibitors. The inhibition efficiency obtained from all method employed are in good agreement. Changes in impedance parameters $\left(\mathrm{R}_{\mathrm{t}}\right.$ and $\left.\mathrm{C}_{\mathrm{d}}\right)$ are indicative of adsorption of Schiff-bases on the metal surface leading to the formation of protective film. Two Schiff-bases are found to adsorb on low alloy steel surface according to the Langmuir adsorption isotherm and thermodynamics calculations revealed that bis-(2-hydroxy-3-methoxy)1,6-diaminohexane salicyladimine had larger adsorption constant and more negative free energy of adsorption than bis-(2-hydroxy)-1,6-diaminohexane salicyladimine.
\end{abstract}

Keywords: Low alloy steel; Schiff -bases; Langmuir ; Inhibition Efficiency.

\section{INTRODUCTION}

Hydrochloric acid is widely used in industry, the most important fields of application being acid pickling, industrial acid cleaning, acid de-scaling and oil well acidizing. Because of the general aggressively of acid solution, inhibitors are commonly used to reduce the corrosive attack on metallic materials. The use of inhibitors is one of the most practical methods of anti corrosion protection for metals and alloys, especially in acid media ${ }^{1-3}$. Most of the well known acid inhibitors are organic compounds containing, phosphor, sulphur, nitrogen and oxygen atoms. The existing data show that most organic inhibitors act by adsorption on the metal surface. The adsorption of inhibitors is governed by the residual charge on surface of metal and the nature and chemical structure of inhibitor and the nature of the aggressive medium. The adsorption organic compounds have been investigated in acid media ${ }^{4-6}$. Most Schiff- bases compounds have been studied as corrosion inhibition of iron and its alloys in acid media ${ }^{6-11}$. They possess and abundance of $\pi$-electrons and unshaped electron pairs on nitrogen and oxygen atoms which interact with d-orbital of iron to provide a protective film.

In the present work, two Schiff -bases compounds with structure depicted in Figure 1. respectively bis-(2-hydroxy-3-methoxy)-1,6-diaminohexane salicyladimine (A1) and bis-(2-hydroxy)-1,6-diaminohexane salicyladimine (A2) as inhibitors for low alloy steel in $1 \mathrm{M} \mathrm{HCl}$ has been studied by electrochemical technique (weight loss measurements, Tafel polarization and $\mathrm{AC}$ impedance measurements) at room temperature.

\section{EXPERIMENT}

\section{Materials and Compounds}

The corrosive medium selected for this study was hydrochloric acid $1 \mathrm{M}$, which was prepared from analytical grade 37 per cent acid concentrated (Merck Germany) in twice-distilled water. The Schiff- bases of A1 and A2 were synthesized using standard methods and each was recrystallized twice from absolute ethanol and finally dried in air ${ }^{12}$. These Schiff-bases compounds were used as inhibitors and were added in $1 \mathrm{M} \mathrm{HCl}$ from $25 \mathrm{ppm}$ to $100 \mathrm{ppm}$. For weight loss measurements, low alloy steel specimens with composition (in wt.\%) C 0.05, Si 0.40, P 0.02, Mn 0.82, Cr 1.95 and Fe (balance) were used with the dimensions $0.2 \times 1 \times 5 \mathrm{~cm}$. These samples were first briefly ground with 300 emery paper, subsequently polished with 1200 emery paper, washed with distilled water, degreased absolute ethanol, dried. The weight loss was determined at room temperature by weighting the cleaned samples before and after hanging the sample in to $100 \mathrm{~mL}$ of corrosive solution in the absence and presence of various concentrations of A1 and A2. After the time elapsed the cleaning procedure consisted of wiping the coupons with a rubber and washing with distilled water and ethanol.

For Tafel polarization and electrochemical AC impedance studies, low alloy steel with dimension of $1 \times 1 \times 1 \mathrm{~cm}$, welded with $\mathrm{Cu}$-wire for electrical connection and was mounted in epoxy resin, to expose a geometrical surface areas of $1 \mathrm{~cm}^{2}$. Prior to these measurements, the exposed surface was pretreated in the same manner as for weight loss experiments.

\section{Electrochemical Measurements}

The electrochemical measurements were conducted using a conventional three electrode cell, using counter electrode $(\mathrm{Pt})$ and a Saturated Calomel Electrode (SCE) as reference electrode and low alloy steel as Working Electrode (WE). A potentiostat /galvanostat ( PAR EG\&G Model 263 A) was used Tafel polarization measurements. All potential values referred to SCE. The experiments were performed in $100 \mathrm{~mL}$ volume cell. The potentials were scanned at a scan rate $1 \mathrm{mV} / \mathrm{s}$ from the corrosion potential value $\left(\mathrm{E}_{\mathrm{cor}}\right)$ in the negative sense and subsequently in the positive sense. For impedance measurements the same equipment was used for the Tafel polarization measurements and with a frequency response analyzer (Princeton applied research Model 1025). Impedance measurements were carried out using AC signals of amplitude $10 \mathrm{mV}$ peak to peak at the open circuit potential in the frequency range $100 \mathrm{KHz}$ to $10 \mathrm{mHz}$. All experimental were carried out at room temperature, with the electrolyte solution in equilibrium with atmosphere. After immersion of specimen, prior to the test measurements, a stabilization period of $30 \mathrm{~min}$ was observed, which proved sufficient for open circuit potential value $\left(\mathrm{E}_{\mathrm{ocp}}\right)$ to attain a stable value.

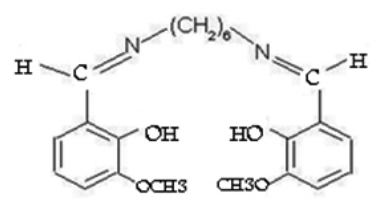

A1

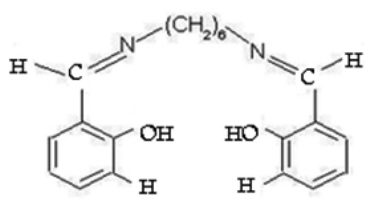

A2
Fig 1. Structure of Schiff bases, A1 and A2

\section{RESULTS AND DISCUSSIONS}

Weight loss

From the experimental data of the weight lost measurement, the protection efficiency $\eta_{w}(\%)(\eta$ per cent) was calculated from the following equation:

$$
\eta_{w}(\%)=\frac{w_{0}-w_{i}}{w_{0}} \times 100
$$

Where $\mathrm{W}_{0}$ and $\mathrm{W}_{\mathrm{i}}$ represent the weight loss of low alloy steel after immersion in $1 \mathrm{M} \mathrm{HCl}^{1}$ without and with inhibitor. Values of $(\eta)$ for all 
investigated concentrations of $\mathrm{A} 1$ and $\mathrm{A} 2$ are summarized in Table. The inhibition efficiency increases with increasing inhibitor concentration. The optimum concentration required to achieve an efficiency of $97 \%$ (for A1) and $92 \%$ (for A2) is found to be $100 \mathrm{ppm}$. The inhibition efficiency by A1 and A2 can be explained in term of adsorption on metal surface.

Table 1. Inhibition efficiencies for corrosion low alloy steel in $1 \mathrm{M} \mathrm{HCl}$ with different concentration of $\mathrm{A} 1$ and $\mathrm{A} 2$ obtained from weight loss measurements.

\begin{tabular}{|c|c|c|}
\hline$\eta_{w}(\%)$ & $\mathrm{C}(\mathrm{ppm})$ & \\
\hline- & - & Blank \\
\hline 91.1 & 25 & \multirow{4}{*}{ A1 } \\
\hline 94.1 & 50 & \\
\hline 96.4 & 75 & \\
\hline 97.1 & 100 & \\
\hline 78.2 & 25 & \multirow{4}{*}{ A2 } \\
\hline 84.3 & 50 & \\
\hline 90.1 & 75 & \\
\hline 92.5 & 100 & \\
\hline
\end{tabular}

Table 2 shows the relationship between protection efficiency and concentrations of $\mathrm{A} 1$ and $\mathrm{A} 2$ in the $1 \mathrm{M} \mathrm{HCl}$. In these concentrations rang, the inhibitors showed high protection efficiency. As the concentration of inhibitors increased, the protection efficiency of A1 and A2 also increased.

\section{Tafel Polarization}

The Tafel plot (the potential E-current density) for low alloy steel in $1 \mathrm{M} \mathrm{HCl}$ in absent and present of different concentration of $\mathrm{A} 1$ and A2 compounds are shown in Figures 2-3. Corrosion current densities were obtained from polarization curves by linear extrapolation of anodic and cathodic branches of Tafel slopes at point $50 \mathrm{mV}$ more positive and more negative than the corrosion potential values $\left(\mathrm{E}_{\text {corr }}\right)$.

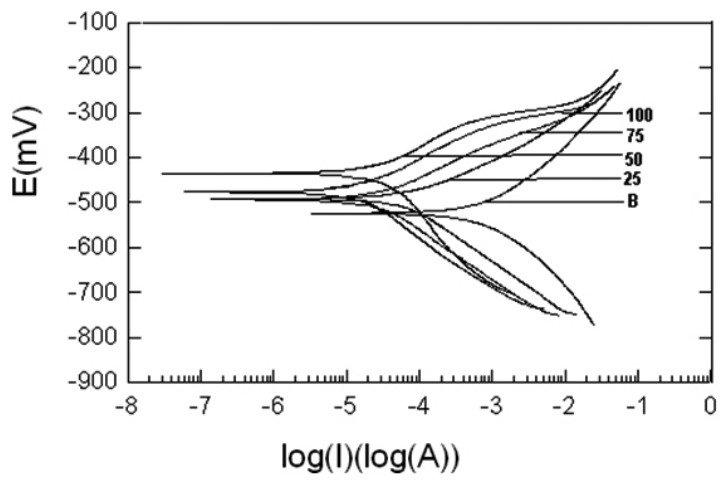

Fig 2. Tafel curves for low alloy steel in $1 \mathrm{M} \mathrm{HCl}$ (B) and containing different concentration of $\mathrm{A} 1$.

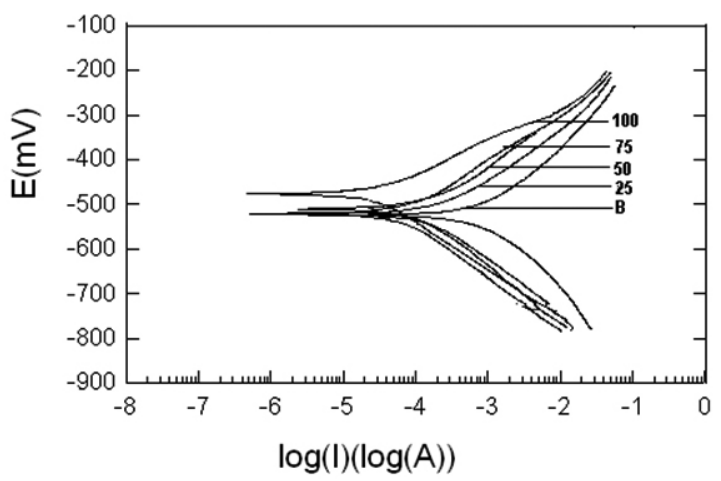

Fig 3. Tafel curves for low alloy steel in $1 \mathrm{M} \mathrm{HCl}(\mathrm{B})$ and containing different concentration of $\mathrm{A} 2$.
The protection efficiency ( $\eta$ per cent) was calculated from the following equation:

$$
\eta_{p}(\%)=\frac{I_{0}-I_{i}}{I_{0}} \times 100
$$

Where $I_{0}$ and $I_{i}$ are an uninhibited and an inhibited in $1 \mathrm{M} \mathrm{HCl}$, respectively. The protection efficiency $\eta_{\mathrm{p}}(\%)$, the corrosion current density $\mathrm{I}_{\text {corr }}$ and corrosion potential value $\mathrm{E}_{\text {corr }}$ derived from Tafel curves are given in Table 2.

Table 2. Tafel polarization parameters for low alloy steel in $1 \mathrm{M} \mathrm{HCl}$ containing different concentration of A1and A2.

\begin{tabular}{|c|c|c|c|c|}
\hline$\eta_{p}(\%)$ & $\left(\mu A \mathrm{~cm}^{\mathrm{I}}{ }^{-2}\right)$ & $\begin{array}{c}E_{\text {corr }} \\
m V \text { vs(SCE) }\end{array}$ & $\mathrm{C}(\mathrm{ppm})$ & \\
\hline- & 880.6 & -525 & - & Blank \\
\hline 91.2 & 74.3 & -493 & 25 & \multirow{4}{*}{ A1 } \\
\hline 94.4 & 49.5 & -496 & 50 & \\
\hline 96.5 & 30.7 & -495 & 75 & \\
\hline 97.9 & 17.6 & -478 & 100 & \\
\hline 79.2 & 184.5 & -523 & 25 & \multirow{4}{*}{ A2 } \\
\hline 85.4 & 128.9 & -511 & 50 & \\
\hline 91.9 & 71.1 & -522 & 75 & \\
\hline 96.1 & 34.5 & -477 & 100 & \\
\hline
\end{tabular}

From Figures 2-3 and Table 2 we see, when the concentration of A1 and A2 was increased, the corrosion current density gradually decreased and the protection efficiency increased. Addition whichever compound produces a positive shift in the $\mathrm{E}_{\text {corr }}$, and as the concentration is increased the corrosion potential value shifts to more noble values (Table 2). Therefore the marked positive shift in corrosion potential value and decrease in current density in the presence of two compounds, suggests these compounds to act as an anodic type inhibitor.

The experimental finding of Tafel curves were in good agreement with the corrosion weight loss data

\section{AC Impedance}

Nyquist plots of low alloy steel in $1 \mathrm{M} \mathrm{HCl}$ in absence and presence of different concentration of Schiff-bases of A1 and A2 are shown in Figures 5-6. The Nyquist plot with a depressed semi-circle with the center under the real axis is characteristic for solid electrode. This kind of phenomenon is known as the dispersing effect ${ }^{13,14}$. One constant phase element (CPE) is substituted for the capacitive element to give a more accurate fit ${ }^{15,16}$. The CPE is a special element whose admittance value is function of the angular frequency $(\omega)$, and whose phase is independent of the frequency. Its admittance and impedance are respectively, expressed as:

$$
\begin{aligned}
& Y_{C P E}=Y_{0}(j \omega)^{n} \\
& Z_{C P E}=\left(1 / y_{0}\right)[(j \omega)]^{-n}
\end{aligned}
$$

Where $\mathrm{Y}_{0}$ is the magnitude of the $\mathrm{CPE}, \mathrm{j}$ is the imaginary number $\left(j^{2}=-1\right), \alpha$ is phase angle of CPE and $n=\alpha /(\pi / 2)$. The factor $n$ is an adjustable parameter. So $n=0$ corresponds to a pure resistor, $n=1$ to a pure capacitor and $n=0.5$ to a Warburge type impedance. Changes in $n$ value have been related with diffusion process, roughness and porosity ${ }^{17}$. For a perfectly smooth electrode, $\mathrm{n}$ would have a value of 1 and the impedance of the CPE would be that of pure capacitor. The value of a real electrode $n$ is less than $1^{18}$. The smaller value of $\mathrm{n}$, the higher the surface roughness, and the depressed the semicircle in the Nyquist plots (Figures 5-6) 17,19. $^{\text {. }}$

The impedance data were interpreted to the suitable equivalent circuit depicted in Figure 4. The equivalent was used to fit the EIS data displaying a capacitive loop. In this circuit, $\mathrm{R}$ is the solution resistance between the working and reference electrode, $R_{t}$ is the charge transfer resistance to the corrosion reaction at metal/electrolyte interface and $\mathrm{CPE}$ is the constant phase element. CPE is substituted for the respective capacitor of $\mathrm{C}_{\mathrm{d} l}$ in order to fit better the better the depressed semicircles ${ }^{16}$ 


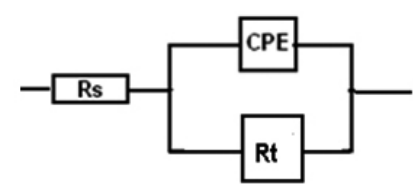

Fig 4. Equivalent circuit used to fit EIS data for low alloy steel displaying a capacitive loop

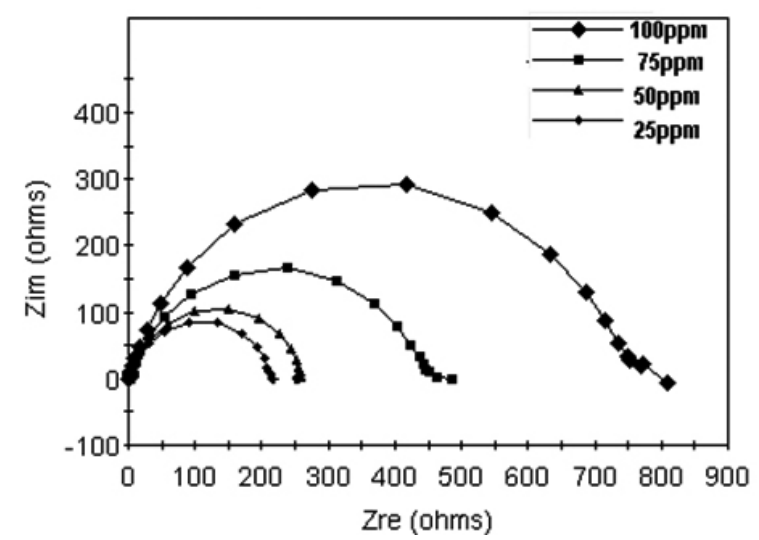

Fig 5. Nyquist plots for low alloy steel in $1 \mathrm{M} \mathrm{HCl}$ containing different concentration of A1.

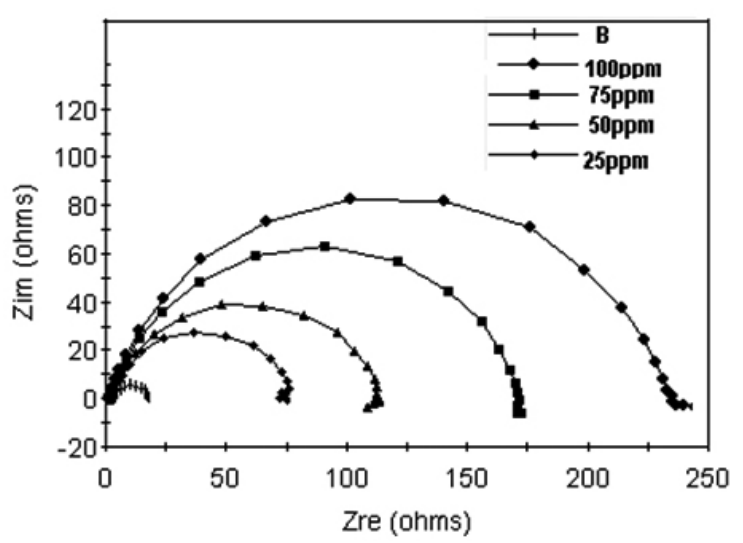

Fig 6. Nyquist plots for low alloy steel in $1 \mathrm{M} \mathrm{HCl}(\mathrm{B})$ and containing different concentration of $\mathrm{A} 2$.

Table 3 Results of Nyquist plots for low alloy steel in $1 \mathrm{M} \mathrm{HCl}$ containing different concentration of A1 and A2 Schiff-bases is shown. The charge transfer resistance was determined from the different in impedance at lower and higher frequencies ${ }^{4}$. The protection efficiency of the investigated inhibitors was determined from the charge transfer resistance values, using the relationship.

$$
\eta_{z}(\%)=\frac{R_{t 0}-R_{t i}}{R_{t i}} \times 100
$$

Where $R_{t b}$ and $R_{t 0}$ are the charge transfer resistances an inhibited and an uninhibited, respectively. The double layer capacitance $\mathrm{C}_{\mathrm{dl}}$ can be calculated from the frequency, $f_{(\max )}$, at which the imaginary part of the impedance $\left(Z_{i}\right)$ is a maximum, using the relationship ${ }^{18}$.

$$
f_{(\max )}=\frac{1}{2 \pi R_{t} C_{d l}}
$$

The inhibition efficiency was evaluated by $R_{t}$ and $C_{d l}$ values of the impedance. The more densely packed the inhibitor surface film, the larger the diameter of the semicircle, which results in higher $R_{t}$ and lower $C_{d l}$ values. Results of the present work showed that the $R_{t}$ value increase with increasing Schiff-bases of A1 and A2 concentrations. While the $\mathrm{C}_{\mathrm{dl}}$ values tend to decrease. The decrease in $\mathrm{C}_{\mathrm{dl}}$ value is due to the adsorption $\mathrm{A} 1$ and $\mathrm{A} 2$ on the metal surface. The adsorbed inhibitor blocks either the cathodic or anodic reaction or both. It is apparent that the inhibition efficiency increases with increasing inhibitor concentration. Table 3 report the parameters, $\mathrm{R}_{t}, \mathrm{C}_{\mathrm{dl}}$, and $\eta(\%)$ derived from the impedance measurements in $1 \mathrm{M} \mathrm{HCl}$ in present of inhibitors, $\mathrm{A} 1$ and $\mathrm{A} 2$.

Table 3. Impedanc parameters for low alloy steel in $1 \mathrm{M} \mathrm{HCl}$ containing

\begin{tabular}{|c|c|c|c|c|}
\hline$\eta_{z}(\%)$ & $\mathrm{C}_{\mathrm{dl}}\left(\mu \mathrm{Fcm}^{-2}\right)$ & $\mathrm{R}_{\mathrm{t}}\left(\Omega \mathrm{cm}^{2}\right)$ & $\mathrm{C}(\mathrm{ppm})$ & \\
\hline- & 710 & 16 & - & Blank \\
\hline 93.1 & 241 & 233 & 25 & \multirow{4}{*}{ A1 } \\
\hline 93.6 & 192 & 250 & 50 & \\
\hline 96.6 & 121 & 484 & 75 & \\
\hline 98.1 & 120 & 807 & 100 & \\
\hline 79.2 & 242 & 77 & 25 & \multirow{4}{*}{ A2 } \\
\hline 85.1 & 193 & 107 & 50 & \\
\hline 90.6 & 184 & 171 & 75 & \\
\hline 93.4 & 142 & 245 & 100 & \\
\hline
\end{tabular}
different concentration of A1 and A2.

The effect of the inhibitor may be due to changes in electric double layer, by reducing metal reactivity, by the inhibitor participation in partial electrode reaction and formation of physical barrier. The values $\mathrm{C}_{\mathrm{dl}}$ decrease as the concentrations of $\mathrm{A} 1$ and $\mathrm{A} 2$ and the inhibition efficiency improves. This decrease can be caused by a decrease in the local dielectric constant and /or the increase in the thickness of the electrical double layer. It shows that the molecules of inhibitor act by adsorption at the solution-metal interface ${ }^{20}$. The capacity of an organic coating is given by the formula:

$$
C_{O c}=\frac{\epsilon \epsilon_{0}}{d}
$$

Where $d$ is the thickness of the organic coating, $C$ is the relative permittivity, and $\epsilon_{0}$ is the permittivity of vacuum. The $\epsilon_{0}$ is constant, therefore the decrease in the values of $\mathrm{C}_{\mathrm{dl}}$ shows that, the adsorption layer formed by $\mathrm{A} 1$ and $\mathrm{A} 2$ on the metal surface is stable and thick ${ }^{21}$.

\section{Adsorption Isotherm}

Adsorption isotherm are very important in determining the mechanism of organo-electrochemical reactions ${ }^{22}$. The adsorption of inhibitors is governed by the residual charge on the surface of the metal and by the nature and chemical structure of inhibitor. In order to obtain the adsorption isotherm, the degree of surface $(\theta)$ for various concentration of the inhibitor has been calculated according to the following equation,

$$
\theta=\frac{c_{d l}-c_{d l(i))}}{c_{d l}}
$$

Where $\mathrm{C}_{\mathrm{dl}}$ and $\mathrm{C}_{\mathrm{dl}(\mathrm{i})}$ are the double layer capacitance values in the absence and presence of the inhibitor.

The value of $\theta$ were tested graphically for fitting a suitable adsorption isotherm. In the present investigation the Frumkin and Temkin isotherms did not give any satisfactory results of the experimental adsorption behavior. Experimental results are in good agreement with the Langmuir adsorption isotherm shown in the following equation: 


$$
\frac{C_{i n h}}{\theta}=\frac{1}{K_{a d s}}+C_{i n h}
$$

Where $\mathrm{C}_{\text {inh }}$ is the inhibitor concentration and $\mathrm{K}_{\text {ads }}$ is the adsorption equilibrium constant. A plot $\mathrm{C}_{\mathrm{in}} / \theta$ versus $\mathrm{C}_{\mathrm{inh}}$ give a straight lines as seem from Figures 7-8 (therefore the adsorption of A1 and A2 from $1 \mathrm{M}$ $\mathrm{HCl}$ on low alloy steel surface obeys Langmuir isotherm.

The value of $\mathrm{K}_{\text {ads }}$ is found as $142.8 \times 10^{3}$ and $41.6 \times 10^{3}(\mathrm{dm} 3 / \mathrm{mol})$ For $\mathrm{A} 1$ and $\mathrm{A} 2$ respectively. The increasing value of $\mathrm{K}_{\text {ads }}$ of $\mathrm{A} 1$ to $\mathrm{A} 2$ reflects the increasing adsorption capability, due to structural formation, on the metal surface ${ }^{23}$. The free energy of adsorption was calculated according to the following equation ${ }^{24}$.

$$
\Delta G_{a d s}=-R T \ln K_{a d s}
$$

Where $\mathrm{R}$ is the universal gas constant and $\mathrm{T}$ is the absolute temperature. These values of $\Delta \mathrm{G}_{\text {ads }}$ were found to be $-29.4 \times 10^{3} \mathrm{KJ} \mathrm{mol}^{-1}$ and $-26.4 \times 10^{3} \mathrm{KJ}$ mol $^{-1}$ for Schiff-bases A1 and A2. The increasing value of $\Delta \mathrm{G}_{\text {ads }}$ (toward the negative) reflects the increasing adsorption capability and the negative value of $\Delta \mathrm{G}_{\mathrm{ads}}$ indicate spontaneous adsorption of inhibitor molecule on the metal surface ${ }^{25}$

The inhibition of active dissolution of the metal is due to the adsorption of the inhibitor molecules on the metal surface forming a protective layer. The inhibitor molecules can be adsorbed onto the metal surface through the electron transfer from the adsorbed species to the vacant electron orbital of low energy in the metal to form a coordinate type link. Iron, is quite well known for its coordination affinity towards nitrogen and oxygen bearing ligands ${ }^{26}$. Therefore adsorption on the metal surface can be attributed to coordination of the organic compounds via phenolic and iminic groups in all two cases. Among these two Schiff-bases, the chelate effect of A1 is higher than A2, as in A1 Schiff-base, two group of $-\mathrm{OCH}_{3}$ have more than A2 Schiff-base and these are very suitable for coordination. The more efficient adsorption in A1 compound is the result of double bonds and electronegative oxygen atoms present in the $\mathrm{A} 1$ to $\mathrm{A} 2$ structure.

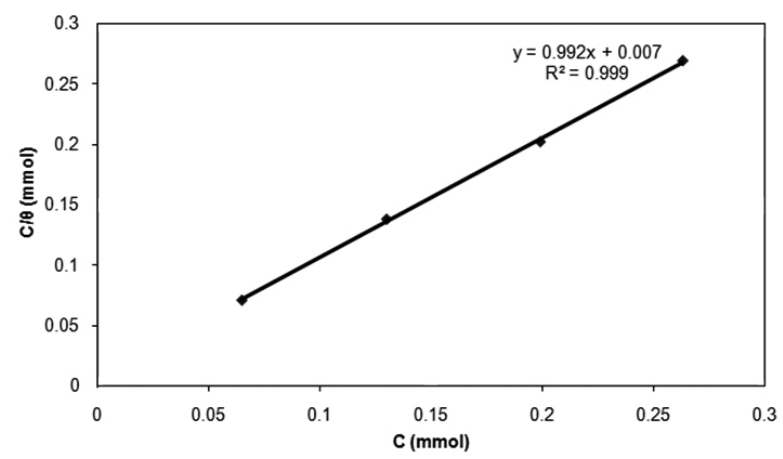

Fig 7. Langmuir adsorption plot for low alloy steel in $1 \mathrm{M} \mathrm{HCl}$ containing different concentration of A1.

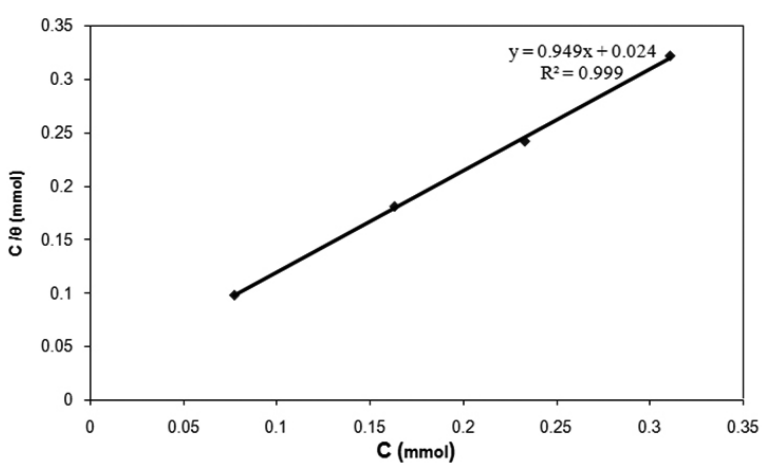

Fig 8. Langmuir adsorption plot for low alloy steel in $1 \mathrm{M} \mathrm{HCl}$ containing different concentration of $\mathrm{A} 2$.

\section{CONCLUSION}

Result prove that Schiff bases, A1 and A2 display inhibitor properties, the effect of $\mathrm{A} 1$ is better than $\mathrm{A} 2$.

The percentage inhibition efficiency is seen to increase with increasing additive concentration due to adsorption of Schiff bases on the low alloy steel surface.

Polarization measurements demonstrate the Schiff bases under investigation act as anodic-type inhibitor.

Impedance measurements indicate that as the additive concentration is increased the charge transfer resistance increases where as the double layer capacitance decreases.

The adsorption process obeys the Langmuir adsorption isotherm.

Comparison of the inhibition efficiencies obtained using ac, dc and weight loss method are in agreement.

\section{REFERENCES}

1- J.I. Bregmann Corrsion Inhibitors, P.T. Macmillan, New York, 1963.

2- C.C. Nathan Organic inhibitors, NACE, Hoston, 1977.

3- V.S. Sastri Corrsion Inhibitors, John Wiley \& Sons, Ontario. Canada, 1998.

4- F. Bentiss, M. Lagrenee, M. Traisnel, J.C. Hornez, Corros. Sci. 41, 789, (1999)

5- I. Rozenfeld Corrosion Inhibitors, Mc Graw-Hill. New York, 1981.

6- T. Mimani, S.M. Mayanna, N. Munichandraiah, J. Appl. Electrochem. 23, 339, (1993)

7- W. Durnie, R. De Marco, A. Jefferson, B. Kinsella, J. Electrochem. Soc. 146, 1741, (1999)

8- H. Shokry, M. Yuasa, M. Sekine, R.M. Isaa, H.Y. El Baradie, G. K. Gomma, Corros .Sci. 40, 2173, (1998)

9- M.N. Desai, M.B. Desia., C.B. Shah, S.M. Desia, Corros. Sci. 26, 827, (1986)

10- M. Hosseini, F.L. Mertens Stijn, M. Ghorbani, M.R. Arshdi, Mater. Chem. Phys. 7, 8800, (2003)

11- F. Baghaei, I. Sheikhshoaie, A. Dadgarnezhad, Asian J.Chem. 3, 224, (2005)

12- A. Schiff, Amm. Chim. 150, 194, (1868)

13- T. Pajkossy, J. Electronal. Chem. 364, 111, (1994)

14- W.R. Fawcett, Z. Kovacova, A. Mtheo, C. Foss, J. Electronal. Chem. 326, 91, (1992)

15- J.R. Macdonald, W.B. Johnso Impedance Spectorscopy, John Willy, New York, 1987.

16- X. Wu, S. Ma, S. Chen, Z. Xu, A. Sui, J. Electrochem. Soc. 146, 1847, (1999)

17- H. Ma, X. Cheng, G. Li, S. Chen, Z. Quan, S. Zhao, L. Niu, Corros. Sci. $42,1669,(2000)$

18- F. Bentiss, M. Traisnel, M. Lagrenee, Corros .Sci. 42, 127, (2000)

19- A.V. Benedetti, P.T.A. Sumodjo, K. Nobe., P.L. Cabot., W.G. Proud, Electrochim. Acta. 40, 2657, (1995)

20- S.S.A. Rehim, H.H. Hassan,M.A. Amin, Appl. Surf. Sci. 187 , 279, (2002)

21- G. Kardas, J. Mate. Science. 41, 337, (2005)

22- B.B. Damaskin, O.A. Petrii, B. Batraktov Adsorption of Organic Compounds on Electrodes, Plenum prees, New York, 1997.

23- S.L.F.A. Da Costa, S.M.L. Agostinho, K. Nobe, J. Electrochem. Soc. 140 , 3483, (1993)

24- M.A. Amin, J. Applied Electrochemistry. 36, 215, (2005)

25- M. Abdullach, Corros. Sci. 44, 717, (2002)

26- B.S. Synder, G.S. Patterson, A.J. Abrahamson, R.H. Holm., J. Am. Chem. Soc. 111, 5214, (1989). 